\title{
OPTIMIZATION OF WAGON CHASSIS
}

\author{
DIVYA PRIYA. G
}

AMET University, Kanathur, Chennai, Tamil Nadu, India

\begin{abstract}
Underground mining is a usual business around the globe, especially in India for iron ore, coal, gypsum etc. The main conditions for underground mining are the transportation of the supplies. Heavy duty coaches, screw type conveyors (or) belt conveyors are most commonly used to carry the supplies. Even for workers - who also use hauler system - heavy duty wagons are the most effective transportation method for underground system. This research recommends modelling and analysis by using 3D modelling software Pro/Engineer of wagon chassis, directing vibrational and structural analysis on heavy duty wagon Chassis by putting on various materials. Two materials design the chassis. They are EN-19 and TitaniumSteel. In this examination, work is done for strain, shear stress, von-misses stresses and total deformations. We are also finding stresses established on Chassis, thermal behavior and mode shape of the chassis. All the miners are using belt and screw type conveyors because of consistent replacement and maintenance of heavy duty wagon chassis.

KEYWORDS: Wagon, Chassis, Dynamic Analysis, Auto CAD, Pro E \& Solid Works
\end{abstract}

Received: Dec 23, 2017; Accepted: Jan 13, 2018; Published: May 07, 2018; Paper Id.: IJMPERDJUN201843

\section{INTRODUCTION}

\section{Mine Transportation}

Developments of transportation followed two different ways in each of the main functions, namely the transportation of persons, ore/coal, equipment and materials. The transportation of ore/coal has either been by belt conveyors, locomotive-hauled mine cars, or rubber-tired trucks. The movement of materials, persons and equipment has been either by movable vehicles/ trackless systems or rail mounted track systems. The transport systems considerations for materials, ore/coal, equipment and persons are main aspects in the decision to use shafts/ drifts for a coal mine. For a vehicle, a speed control is given, which creates an input signal representative of the desired speed.

Manufacture and design of a wide product choice of transportation systems for materials and men, with wagons fit for subversive, tunnel and surface applications. Safe, reliable and robust wagons are offered by rope hauled transportation technology with specifications of equipment designed to encounter the most difficult mining atmosphere. The Qualter Hall systems contain in additional of 100 rope hauled transport installations functioning internationally to support materials vehicles, man riding trains, brake anchor cars, chock transporters and clip tugs.

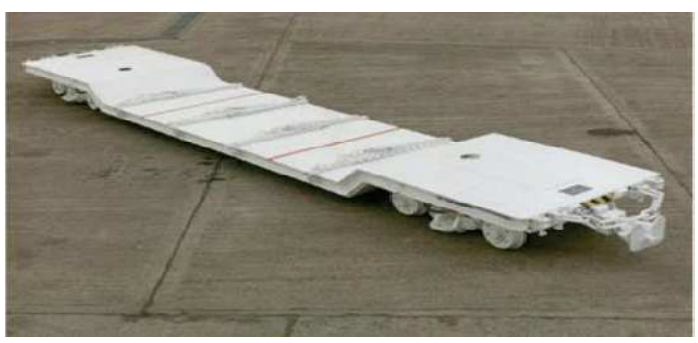

Figure 1: Braked Chock Transporter 


\section{Chassis}

High strength steel plates of IS: 2062 E350BR make Chassis. All cross members and longitudinal are of rectangular box units made by $10 \mathrm{~mm}$ thick plates. The upper and lower portion of the chassis is enclosed with $8 \mathrm{~mm}$ dense steel plates. A load of $20 \mathrm{~T}$ like chock support power packs can be carried by well thickened chassis. Railed brake bogies mount the chassis. Water drainage holes, which are correct sized are positioned in the chassis wells to avoid the water collection. Filter, hydraulic oil tank with hand pump, and pressure gauge are mounted in the Chassis. To accommodate one Governor Bogie and one standard Pivot bogie, substantial turntable housing at each end of the chassis is given.

Analysis should be done on chassis with variant materials, as per the requirements and directions of Research \& Development department to suggest the best material that can resist the motionless loads. New materials such as Titanium Steel (Ti-6Al-4V) materials and regular material such as EN19 stainless steel materials are used. Dynamic analysis should be done with the two materials to examine the physical and vibrational characters.

\section{MODELLING OF CHASSIS}

With the help of Pro/E software, chassis is carried out. Initially, the Chassis is designed as per the statistics provided by the company. The drawing profiles are brought in from the CMM data and suitable lines are produced with reference to the manage point. The sketch is now changed to portion by the boundary option usage, which results in the Chassis creation with essential shape. The chassis is spotted which provides number of similar objects in necessary directions. The complete procedure is provided below with illustrations.

\section{Step by Step Procedure of Part Modelling Using Pro/Engineer}

- $\quad$ Pts file is imported after opening the file, using coordinate datum point tool.

- Using datum tool, Chassis are generated with the reference of coordinate points.

- Portions are segregated with the use of split selection for surface generation.

- Generation of surfaces takes place using two direction method in all directions.

- Surface portion is transformed into solid using solidifies and merge options.

- Shaft is equipped as per the drawing sheet of the company using chamfer, revolve and extrude options.

\section{Model}

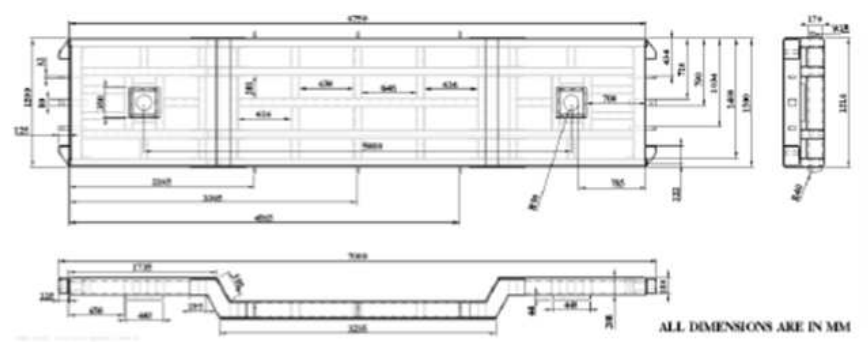

Figure 2: Image Showing Drawing of Chassis

The company gave the drawing of the chassis with all the expected views. Initially, the model is formed in the sketcher with suitable proportions as displayed in figure 2 . 


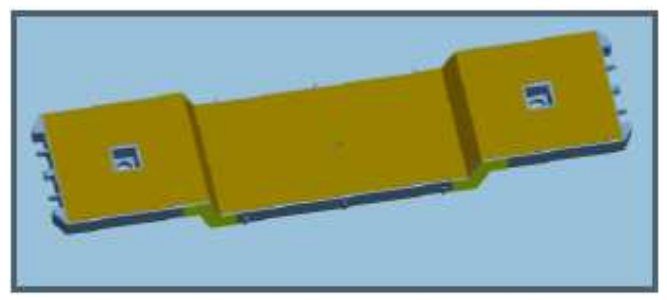

Figure 3: Image Showing Generated Part of Chassis View 1

The sketched portion is now extruded with sizes according to the drawing sheet. The extrude selection adds the material in the reverse direction and to finish the part, other features are used.

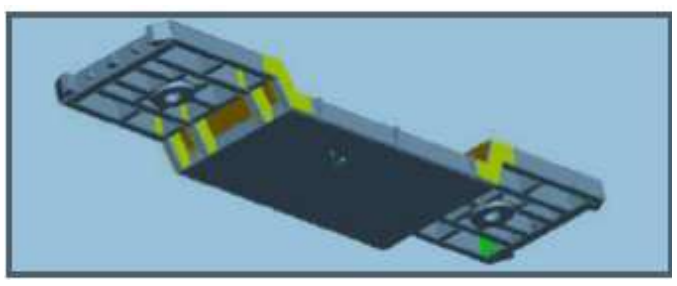

Figure 4: Image Showing Generated Part of Chassis View 2

\section{SPECIFICATIONS OF CHASSIS}

\section{Loading Capacity: 20 Tonne}

Overall Length: $7000 \mathrm{~mm}$

Flat Width: $1500 \mathrm{~mm}$

Flat Length: $3500 \mathrm{~mm}$

Rail Gauge: 900 mm

From rail top flat height: $362 \mathrm{~mm}$

The chassis was designed to be compensated and weight bearing, thus eradicating the smolder box heavy propensity model locomotives. Both tender and loco chassis are stamped in $0.38 \mathrm{~mm}$ nickel silver. Both chassis are "Fold up" structure removing the necessity for a costly frame assembly jig. This chassis provides important extra information to the model beneath the footplate. All six wheels are compensated by the tender chassis.

\section{Boundary conditions}

- All wheels' bottom faces are to be fixed in all sides and 20Tonnes to be used at center flat sides of Chassis.

- $\quad$ From top side, load 20Tonnes.

\section{MATERIAL PROPERTIES}

As per the information provided by the company, the supplies used for the chassis is EN19 stainless steel and IS 2062 Mild Steel. This is unable to transport the heaps which in turn leads to breakages on the chassis and sometimes, uneven breakdowns. EN19 stainless steel is an alloy of nickel, copper, molybdenum and chromium.

Titanium Steel (Ti-6Al-4V) is the second material, which is a medium carbon ferrous super alloy. Due to their low density, high strength and excellent corrosion resistance, titanium alloys are striking structural materials. In many 
application, the high strength-to-weight ratio of titanium alloys allows them to replace steel necessitating increased strength and breakage durability. Titanium alloys are about partial as weighty as nickel and steel -base super alloys, gaining outstanding strength-to-weight ratios.

Table 1

\begin{tabular}{|l|c|c|}
\hline \multicolumn{1}{|c|}{ Properties } & EN19 Stainless Steel & Titanium Steel (Ti-6Al-4V) \\
\hline Yield strength & $3.48054 \mathrm{e}+008 \mathrm{~N} / \mathrm{m}^{\wedge} 2$ & $1.03421 \mathrm{e}+009 \mathrm{~N} / \mathrm{m}^{\wedge} 2$ \\
\hline Tensile strength & $7.18083 \mathrm{e}+008 \mathrm{~N} / \mathrm{m}^{\wedge} 2$ & $1.22 \mathrm{e}+009 \mathrm{~N} / \mathrm{m}^{\wedge} 2$ \\
\hline Compressive strength & - & $1.09 \mathrm{e}+009 \mathrm{~N} / \mathrm{m}^{\wedge} 2$ \\
\hline Elastic modulus & $2.5 \mathrm{e}+011 \mathrm{~N} / \mathrm{m}^{\wedge} 2$ & $1.04 \mathrm{e}+011 \mathrm{~N} / \mathrm{m}^{\wedge} 2$ \\
\hline Poisson's ratio & 0.29 & 0.33 \\
\hline Mass density & $7870 \mathrm{~kg} / \mathrm{m}^{\wedge} 3$ & $4820 \mathrm{~kg} / \mathrm{m}^{\wedge} 3$ \\
\hline Shear modulus & $8 \mathrm{e}+010 \mathrm{~N} / \mathrm{m}^{\wedge} 2$ & $4 \mathrm{e}+010 \mathrm{~N} / \mathrm{m}^{\wedge} 2$ \\
\hline
\end{tabular}

\section{ANALYSIS OF CHASSIS}

Initially, the IGES file is brought into the COSMOS software to begin the recreation work. The materials are given to the structural and assembly, and vibrational and impact analysis is performed. The material and its features are applied to the material to begin the process of simulation. Then, the suitable limitations must be provided to all DOF. The loads are now applied at the appropriate locations with SI units. After the weight is applied, meshing must be performed with element size and predefined mesh controls. The analysis is now done in post processing as all the pre processing is performed.

\section{Structural Analysis}

\section{Step by Step Procedure of Structural Analysis}

- IGES file should be opened; select ok to restore the assembly in cosmos in simulation works.

- Choose new study and choose static, specific necessary name to analysis.

- Choose assign materials to generate a new substance in personalized material wizard.

- All the properties of materials should be entered in required fields.

- Choose constraints wizard and select fix constraint; then, select essential outsides on shaft to capture all DOF.

- Choose options of mesh apply mesh controls, select standard mesh and stipulate element size ok, choose create mesh option.

- Select run.

- After successful analysis completion, right click on stress. Then, select edit definition option, select essential units and scale factors ok.

- Choose external load wizards, followed by selecting pressure trailed by SI units. Then, select blade surfaces and specify pressure value as ok.

\section{Vibrational Analysis}

A new study is produced after effective closure of static analysis. The model that is saved in IGES format is brought in again and all the substances and properties are provided. The meshing is performed with the stated element 
distances. The constraints and loads are now applied to the shaft and blades. In vibrational analysis, the simulation provides5 mode shapes explaining extreme movement of sample at a specific frequency. Below are the mode shapes for all the materials.

\section{Step by Step Procedure of Vibrational Analysis}

- IGES file should be opened and select ok to renew the assembly in simulation works in cosmos.

- Choose new study and choose rate, exact essential name to analysis.

- Choose allot materials and generate a new material in personalized material wizard.

- All the properties of materials should be entered in specified fields.

- Choose constraints wizard, choose fix limitation and choose essential surfaces on shaft to seize all DOF.

- Choose mesh options apply mesh controls, choose standard mesh and mention the size of element as ok, choose create mesh option.

- Select run.

- Right click on displacements after the successful completion of analysis; select edit definition option, choose necessitated units and scale factors ok.

After taking new study, choose assign materials. Then, generate a new substance in personalized material wizard. In specified fields, enter all the material properties. With a mentioned element size, the solid meshing is now performed similar as in the case of structural analysis. The application of loads is different.

\section{Impact Analysis}

Impact analysis is performed for the assembly of trolley with two materials Titanium alloy and EN19 steel to find the characteristics of structure. Initially, the model is brought in to the Cosmos and enters all the materials properties in required fields. Strain and displacements are determined after successful running of simulation stress.

\section{Step by Step Procedure of Thermal Analysis}

- IGES file should be opened, select ok to renew the assembly in simulation works in cosmos.

- Choose new study and choose thermal, necessary name to analysis.

- Choose assign materials and generate a new material in personalized material wizard.

- All the properties of materials should be entered in required fields.

- Choose constraints wizard, choose convection and select essential surfaces on trolley to apply load values.

- Choose external load wizards, select temperature followed by SI units, then blade surfaces and mention temperature value ok.

- Choose options for mesh apply mesh controls, select standard mesh and specify size of element ok, select create mesh option. 
- $\quad$ Select run.

- Right click on temperature after successful completion of analysis, then select edit definition option, then select essential units and scale factors ok.

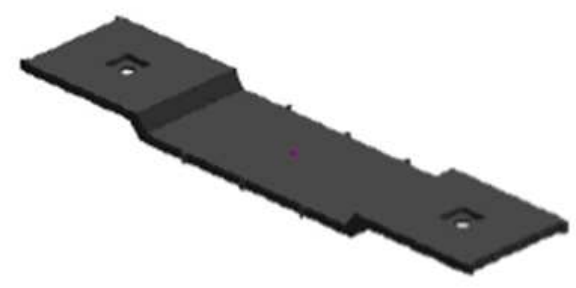

Figure 5: Impact Analysis of the Heavy Duty Chassis

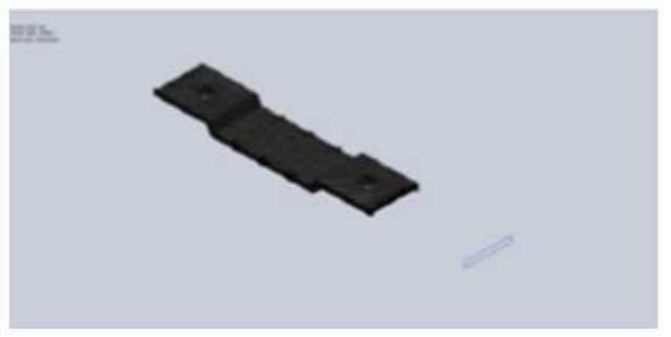

Figure 6: Impact Analysis of Heavy Duty Chassis of Meshed Modal

The above figure displays the meshed model. To mesh the components, default solid Brick element was used. The revealed mesh process was called Tetra Hydra Mesh. Meshing is used to decompose complex issues into no. of smaller issues created on finite element method.

\section{RESULTS AND DISCUSSIONS}

A report is created when the simulation is finished to find the results. Initially, the static analysis is performed for different types of materials. It provides stresses established in the chassis and trolley assembly, displacement and strain values. Now all the stress, strain and displacement values are displayed in the below figures.

\section{Static Analysis}

Static analysis is performed by rubbing on present materials EN19 Stainless Steel and IS 2062 Mild steel for bogie and chassis as per the information provided by the company.

\section{Result of Impact Analysis of Heavy duty Chassis}

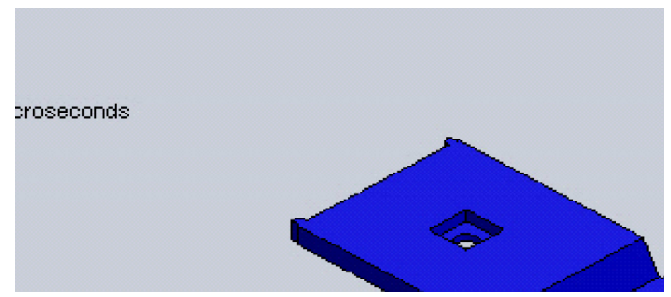

Figure 7: Stress in Titanium Steel

Titanium Steel (Ti-6Al-4V) stress values can be determined from the Figure 7. It can be detected that the maximum and minimum values of MAX is 236.427 N/mm2 and Von Mises Stress are MIN is $9.11473 \mathrm{e}-016 \mathrm{~N} / \mathrm{mm}^{\wedge} 2$. 


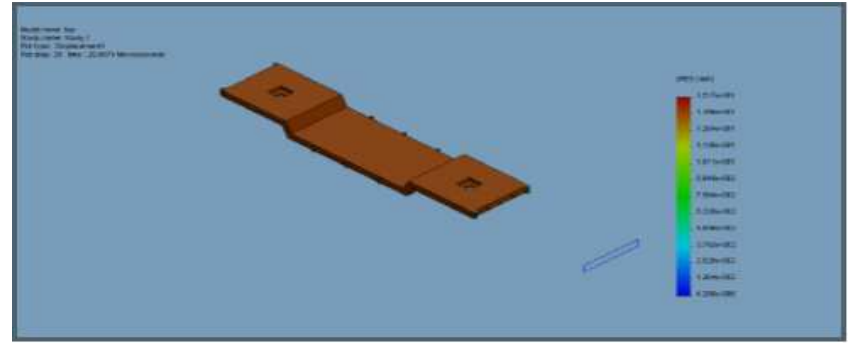

Figure 8: Displacement for Titanium Steel

The displacement value of Titanium Steel (Ti-6Al-4V) can be determined from the figure 8 . It is seen that the maximum displacement value is $0.15168 \mathrm{~mm}$.

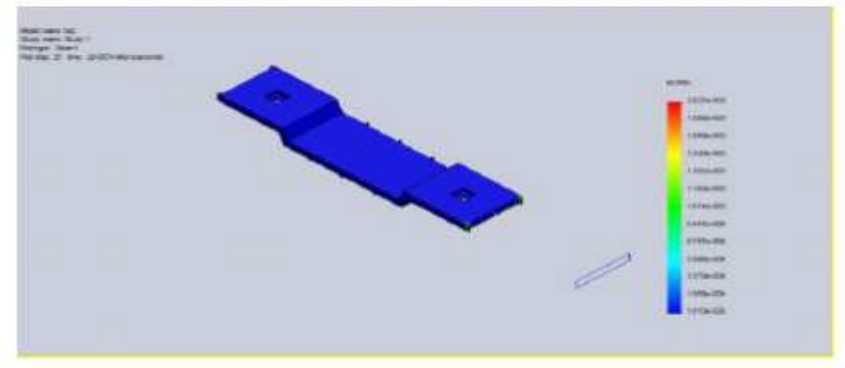

Figure 9: Strain for Titanium Steel (Ti-6Al-4V)

The strain values of Titanium Steel (Ti-6Al-4V) can be determined from the above figure. It can be seen that the maximum and minimum values of Strain 0.00202721 and $1.06962 \mathrm{e}-020$, respectively.

\section{Tables and Graphs}

The meshing is performed successfully after the loads are applied to the imported model, and the outcomes are collected. Initially, the static analysis is performed for chassis with available materials IS 2062 Mild steel and EN19 Stainless Steel. The results are shown below.

Table 2: Result Summary for Static Analysis

\begin{tabular}{|c|l|c|c|c|}
\hline SI. No & \multicolumn{1}{|c|}{ Material } & Stress N/Mm^2 & Strain & Displacement Mm \\
\hline 1 & $\begin{array}{l}\text { EN19 Stainless Steel and } \\
\text { IS 2062 Mild steel }\end{array}$ & 57.5453 & 0.000590442 & 0.473867 \\
\hline
\end{tabular}

The above table provides the differences in strain, stress, displacement for all the two materials - IS 2062 Mild steel and EN19 Stainless Steel.

\section{CONCLUSIONS AND SCOPE FOR FUTURE WORK}

To recognize material for stress produced portions and to evaluate the new model of 20 tonnes heavy duty Chassis. Material optimization and evaluation is performed with the use of FEM based analysis cosmos work bench. The below steps are performed to find the results.

- Model and structural analysis is performed on complete assembly to find the areas concentrated on stress from the results of analysis; maximum stress concentration is facing wheel assembly.

- To witness structural characteristics in impact situations, impact analysis is performed. 


\section{The Following Conclusions can be Drawn from the above Work}

- Modal and static analysis is performed on chassis with the difference of material.

- From Structural analysis, it is found that the von-misses stress of chassis for EN-19 and Titanium Steel (Ti-6Al$4 \mathrm{~V})$ is $57.545 \mathrm{~N} / \mathrm{mm} 2$.

- From Structural analysis, it is observed that the displacement of chassis for EN-19 and Titanium Steel (Ti-6Al$4 \mathrm{~V}$ ) is $0.473867 . \mathrm{mm}$.

- From Structural analysis, it is seen that the chassis strain for EN-19 and Titanium Steel (Ti-6Al-4V)is 0.00059004 .

- From Impact analysis, it is found that the stress of Chassis for EN-19 is $57.545 \mathrm{~N} / \mathrm{mm} 2$.

- From Impact analysis, it is found that the displacement of chassis for EN-19 is $0.15168 \mathrm{~mm}$.

- From Impact analysis, it is found that the strain value of chassis for EN-19 is 0.00202721. mm2.

\section{Scope for Future work}

Using different materials rather than used materials for the expansion of finite element formulation of 20 tonnes heavy duty trolley.

\section{REFERENCES}

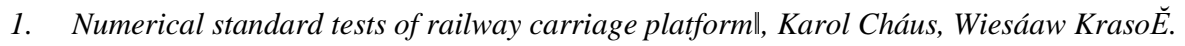

2. Adhesive bonded hot dip zinc coated sheet and titanium sheet joint strength - numerical analysisl, Anna Rudawska, Hubert DĆbsk.

3. Modeling and Analysis of the Nonlinear Dynamics of the Trans rapid and Its Guide wayl, Michael Dellnitz, Florian Dignath, Kathrin Flaßkamp, Mirko Hessel-von Molo, Martin Kr uger, Robert Timmermann, and QinghuaZheng.

4. Reliability Analysis for Degradation of Locomotive Wheels using Parametricl, Bayesian Approach Jing Lin, Matthias Asplund and Aditya Parida.

5. Optimization of twenty tonnes heavy duty trolley by using finite element techniquell Puramarambabu M. TECH, Sri D. Vijay Praveen M. TECH, Dr M. Venkateswararao M. TECH., Ph. D.

6. Ron Cobden, Alcan, Banbury, -luminum: Physical Properties, Characteristics and Alloys.

7. Saeed Moaveni, Finite element analysis, theory and application with Ansys.

8. Martin, Shynee, et al. "Growth Of Literature On Aerodynamic Research: A Scientometrics Study."

9. Paletisrinivas, S. Krishnachaitanya and D. Rajeshkumar, finite element analysis using ANSYS.

10. The finite Element Methodology, SINGIRESU S. RAO.

11. Solid Works 2013 for Engineers and Designers by Prof. Shaun Tickeo \&Sandeep Prandas. 